\title{
Biomarkers towards Ovarian Cancer Diagnostics: Present and Future Prospects
}

\author{
Meenal Rastogi ${ }^{1}$, Sameer Gupta ${ }^{2}$ and Manisha Sachan ${ }^{1 *}$. \\ IDepartment of Biotechnology, Motilal Nehru National Institute of Technology, India; ${ }^{2}$ Department of Surgical \\ Oncology, King George Medical University, Lucknow, India.
}

\begin{abstract}
Ovarian carcinoma accounts for highest mortality of all gynecologic malignancies as the disease is asymptomatic until late stages. Biomarkers such as CA-125 and HE4 are being currently used for diagnosis of ovarian cancer, but they show contradicting diagnostic accuracy. Therefore other biomarkers have been investigated for early detection of this disease, but no success has been obtained and no test has yet been recommended for screening a general population. In this instance, aptamers can be effectively used to identify tumor-specific antigens for early diagnosis and targeted therapy of ovarian cancer. This article provides an overview of the biomarkers/panels being explored as well as the potential of aptamers to improve current long-term survival rates of ovarian cancer.
\end{abstract}

Key words: Ovarian cancer, aptamers, DNA methylation, CA-125, HE4

\footnotetext{
*Authors for correspondence: manishas77@rediffmail.com
} 


\section{INTRODUCTION}

With over 22,000 new cases reported per year in the US, ovarian cancer is the fifth most common cause of cancer related death in the US and accounts for $5 \%$ of cancer deaths among women according to Cancer Facts and Figures 2016, by the American Cancer Society. Ovarian cancer accounts for the highest mortality of all gynecologic malignancies as it is difficult to detect ovarian cancer at an early stage due to vague clinical symptoms. The 5-year survival rate for early stage ovarian cancer is approximately $92 \%$, but most patients are diagnosed with advanced stage disease and the 5-year survival rate is only $30 \%$. Most ovarian cancers are developed from three categories of cells: epithelial cells, sex cord stromal cells, and germ cells. Among them, epithelial ovarian cancer (EOC) accounts for 90\% cases. EOCs are divided into five subtypes: 1) serous: $\sim 50 \%$; 2) mucinous: 5-10\%; 3) endometrioid: $10-25 \%$; 4) clear cell: 4-5\%; and 5) transitional cells: rare ${ }^{1}$. EOC responds to cytoreductive surgical resection and chemotherapy in $70 \%$ of cases, however, less than $20 \%$ of women with advanced ovarian cancer (stage III and IV) can be cured. $90 \%$ of patients can be cured in cases, where the disease is limited only to the ovaries (stage I). Irrespective of radical surgery and adjuvant systemic chemotherapy, most patients develop recurrent disease.

Owing to the low prevalence of ovarian cancer an effective screening tool for early diagnosis of the disease should have a specificity of at least $99.6 \%$, sensitivity of at least $75 \%$ and a positive predictive value (PPV) of at least $10 \%^{2}$. Effective screening methods for early diagnosis of cervical cancer have reduced its incidence in Korea ${ }^{3}$. Therefore, an effective screening strategy is urgently required for detection of early stage of disease with adequate sensitivity that could significantly reduce mortality rates. Currently, the pelvic examination, transvaginal ultrasonography (TVUS) and serum CA-125 levels are the standard modalities in detecting ovarian cancer. CA-125 is only elevated in $47 \%$ early-stage disease, whereas its level is elevated in $80-90 \%$ cases of advanced-stage of ovarian cancer. But it is also expressed by a number of other cell types and in benign conditions.

The use of a single screening test alone cannot meet with any existing screening paradigm. Many biomarkers have been considered and further validation needs to be done. Recently, researchers have exploited aptamers for the detection, imaging and targeted therapy of cancer. These short singlestranded oligonucleotides (RNA, DNA or peptides), selected from a large pool of sequences by SELEX, can bind to many types of different targets, extending from small molecules to proteins or nucleic acid structures. These probes can specifically bind to the biomarkers expressed by targeted tumor cells. This review aims to develop an understanding of the biomarkers/panels being investigated as well as the prospective of using aptamers for the early detection and diagnosis of ovarian cancer that could have an effective impact on the mortality.

\section{CURRENT APPROACHES FOR THE DETECTION OF EARLY-STAGE OVARIAN CANCER USING CA-125 AND HE4}

\section{CA-125 (Cancer Antigen 125)}

CA-125 was first described by Rober Bast and colleagues, as an antigen that increases in the majority of patients with epithelial ovarian cancer. Later shown to correlate with the course of the disease, CA-125 is now deemed as a classic, "gold standard" tumor biomarker. The CA-125 molecule is a high molecular weight membrane glycoprotein that shows sensitivity between $50-60 \%$ at $90 \%$ specificity in early stage postmenopausal women and $75-90 \%$ in patients with advanced stage disease $^{4}$. It is the only biomarker currently widely used in cancer therapy. However, CA-125 is not exclusively expressed on ovarian tumor cells, but also by a number of other cell types including the pleura, peritoneum and mullerian epithelia. Using CA-125 for early detection can precede the clinical diagnosis by more than a year. In addition, analysis of CA-125 level has been useful in monitoring the recurrence of disease. However, several factors undermine the significance of CA125 as an early detection biomarker such as the absence of its expression in about $20 \%$ of ovarian cancer and elevated expression in some benign conditions (liver cirrhosis, endometriosis, peritonitis). Moreover, fluctuation in CA-125 level is also associated with the menstrual cycle and pregnancy ${ }^{5}$. CA-125 as an individual marker is not sufficiently sensitive to detect all cases of earlystage ovarian cancer. Therefore, no CA-125 based screening techniques are as yet recommended for 
the general population. However, various clinical trials are evaluating the sensitivity of CA-125 in concurrence with other markers to increase its sensitivity as an early detection biomarker.

Generation of tools implementing computer technology and statistical methods have been found effective in boosting the sensitivity of CA125 while maintaining good specificity. Risk of Ovarian Cancer Algorithm (ROCA) is a computerized algorithm that enhances the sensitivity of CA-125 up to $86 \%$ in early detection of ovarian cancer ${ }^{6}$. Based on the level of CA-125 (both current and previous) and their ROCA scores, women are triaged into low risk, high risk and intermediate risk and then referred for further procedures such as annuals, TVUS or repeated evaluations of CA-125 level, respectively. The threshold level considered for CA-125 being 35 $\mathrm{U} / \mathrm{ml}$.

\section{HE4 (Human Epididymis Protein 4)}

HE4, a member of the WFDC family of proteins (whey acidic four-disulfide core), is overexpressed in ovarian carcinoma. Moore et al. analyzed the serum and urine samples from 259 patients with adnexal masses and noticed that HE4, as a single marker, had the highest sensitivity of $72.9 \%$ (95\% specificity). However, combined CA-125 and HE4 yielded the highest sensitivity of $76.4 \%$ (specificity 95\%) suggesting that their combination predicts malignancy more accurately than either alone ${ }^{7}$. Likewise, Azzam et al. observed the diagnostic sensitivity of HE4 was higher than CA-125 (82.5 vs. $76.6 \%$ for HE4 and CA-125, respectively) at $95 \%$ specificity in sera of patients with ovarian carcinoma but was lower in benign cases $^{8}$. Conversely, when 373 women with suspicious malignant ovarian cyst were analyzed by Kristjansdottir et al., their combination resulted in a downfall in the sensitivity $(48.3 \%)$ in diagnosis of early stage type I EOC as compared to early stage type II EOC ( $85.2 \%$ sensitivity) at $75 \%$ specificity 9 . The diagnostic accuracy of HE4 has been contradicting and further assessment is needed. HE4 can also be detected in urine at $94.4 \%$ specificity, including $86.6 \%$ with stage I/II and $89.0 \%$ with stage III/IV disease and including $90.5 \%$ of patients with serous ovarian carcinoma similar to serum assays ${ }^{10}$. Besides, it complements serum assays as it was found useful in monitoring the clinical recurrence in cases that showed normal HE4 and CA-125 serum levels.
Ova1 is an FDA approved test for identifying high risk ovarian tumors before any surgical procedures. This quantitative test combines measurements of five proteins: CA-125, apolipoprotein A1, transthyretin, beta-2 microglobulin and transferrin. OvaCalc software using an algorithm and the values of these five analytes interprets the results. Oval score greater than 5 for premenopausal women and 4.4 for postmenopausal women, is considered with higher risk of malignancy. Ova1 demonstrated $92.5 \%$ sensitivity, but lower specificity of $42.8 \%$ in a trial conducted on women $(n=516)$ referred for surgery by physicians ${ }^{11}$. Risk of Malignancy Algorithm (ROMA) was developed by combining CA-125, HE4 levels and patients' menopausal status. A ROMA score (numerical) is calculated from the predictive index and on the basis of these scores, women who present with a pelvic mass are categorized into high risk or low risk groups. Cutoff values of 1.31 and 2.27 are considered for premenopausal and postmenopausal patients, respectively. ROMA has a greater specificity $(75 \%$ versus 43\%) than $\mathrm{Ova}^{12}$; however, further exploration is necessary.

\section{OTHER BIOMARKERS USED FOR EARLY DETECTION OF OVARIAN CANCER}

With the advent of new technologies such as mass spectrometry and protein microarrays within proteomics, new biomarker candidates are being discovered and panels have been developed in an attempt to increase the sensitivity for early-stage ovarian cancer detection. Havrilesky et al. evaluated a panel of biomarkers with HE4, PAI-1, Glycodelin, MUC1, MMP7, Inhibin A, SLPI, Plau-R, and CA-125 in 200 women with ovarian cancer. Based upon ROC curve analysis, the sensitivity/specificity was found within the range of $59.0 \% / 99.7 \%$ to $80.5 \% / 96.5 \%$ for stage I disease $^{13}$. Yurkovetsky et al. proposed a multibiomarker panel with CA-125, HE4, CEA, and VCAM-1 that could significantly distinguish patients with early-stage ovarian cancer and healthy subjects with $86 \%$ sensitivity at $98 \%$ specificity ${ }^{14}$. More recently, a biomarker panel comprising CA-125, HE4, MMP-7, and CA72-4 studied using immunoassays in pretreatment sera from 142 stage I OC cases and 217 healthy controls showed $83.2 \%$ sensitivity at $98 \%$ specificity ${ }^{15}$. The description of the biomarkers for 
early diagnosis of ovarian cancer has been shown in figure 1 .

\section{Mesothelin}

Mesothelin is a cell surface glycoprotein, expressed by the mesothelial cells lining the pleura, peritoneum and pericardium in normal tissues. McIntosh et al. detected increased level of serum mesothelin in $60 \%$ of ovarian cancer with $98 \%$ specificity. A combination of mesothelin and CA-125 was superior in early detection and diagnosis of cancer than using either marker alone $^{16}$. In a study of 44 ovarian tumor specimens, Obulhasim et al. found mesothelin was expressed in $100 \%$ of serous cystadenocarcinoma and $100 \%$ of serous borderline tumors of the ovary. Diverse levels of methylation/hypomethylation at $\mathrm{CpG}$ sites were observed in the promoter region of mesothelin in ovarian and endometrial cancer ${ }^{17}$. Mesothelin plays a significant role in tumor metastasis, cancer cell survival and proliferation, and drug resistance ${ }^{18}$. Studies have revealed that higher level of mesothelin denotes poor overall survival in patients with advanced stage ovarian cancer. Moreover, mesothelin was elevated in $42 \%$ of urine assays in contrast to $12 \%$ of serum assays of early-stage ovarian cancer patients with $95 \%$ specificity ${ }^{19}$.

\section{Transthyretin}

Transthyretin (TTR) is a prealbumin that was traditionally seen as a biomarker of nutritional status. Zhang et al. identified three biomarkers that simultaneously improved the detection of earlystage ovarian cancer, particularly test specificity. They were characterized as acute phase reactants. Amongst them, transthyretin was shown to be downregulated in the $\mathrm{EOC}^{20}$. TTR is the major carrier for serum thyroxine and facilitates the transport of retinol via retinol binding protein. Lower level of retinol protein has been correlated with an increased rate of malignant transformation in ovarian epithelium. Transthyretin showed $47 \%$ sensitivity at $95 \%$ specificity in ovarian cancer ${ }^{21}$. Nosov et al. combined transthyretin with CA-125, ApoA1 and transferrin. In this study, 358 serum specimens were analyzed and the panel exhibited $96 \%$ sensitivity and $98 \%$ specificity for detection of early disease ${ }^{22}$. When combined with CA-125, ApoA1 and connective tissue-activating protein III, in another study consisting of 136 patients with stage I ovarian cancer, the sensitivity of $84 \%$ was observed at $98 \%$ specificity ${ }^{23}$.

\section{Apolipoprotein A1 (ApoA1)}

ApoA1 is a major constituent of high-density lipoproteins in plasma. Its level has been reported to decrease in the sera of patients with ovarian cancer. The mechanism of its association with cancer remains unclear; though it has been proposed to be associated with free radicalmediated damage to the cellular membranes, resulting in lipid peroxidation ${ }^{24}$, thereby inducing mutations in oncogenes as well as tumor suppressor genes. When ApoA1 was combined with CA-125 and TTR, not only a significant improvement was observed in the overall sensitivity and specificity $(93.9 \%$ sensitivity at 95\% specificity), but the panel was also sufficient for maximum separation between non-cancer and stage I+II or all stages (I-IV) of the disease ${ }^{25}$. Recently, Pal et al. proposed a multiplexed fluorescence spectroscopic based assay to detect $\beta 2-$ microglobulin ( $\beta 2-\mathrm{M}), \mathrm{ApoA} 1$ and CA-125 at an early stage of ovarian cancer followed by Surface Plasmon Resonance spectroscopy (SPR) for comparative analysis. The panel achieved sensitivity up to $94 \%$ at $98 \%$ specificity; furthermore, the assay was cost effective compared to previously available Ova1 test ${ }^{26}$.

\section{Transferrin}

Transferrin, essentially synthesized in hepatocytes, is responsible for transporting plasma iron into the cell and plays a significant role in cell differentiation and proliferation ${ }^{27}$. Ahmed et al. reported the downregulation of transferrin in the serum of patients with ovarian cancer ${ }^{28}$. Transferrin promotes tumor development and survival via antiapoptotic effect. The combination of CA-125, transferrin, TTR and ApoA1, using proteomic analysis yielded a sensitivity of $89 \%$ at specificity of $92 \%$ for early detection of ovarian cancer ${ }^{29}$.

\section{B7-H4}

B7-H4, formerly known as DD-O110, is a 282 amino acid protein expressed in activated $\mathrm{T}$ cells that acts as a negative regulator of T-cell immunity by inhibiting $\mathrm{T}$-cell proliferation, cytokine production, and cell cycle progression. B7-H4 may promote malignant transformation. Using ELISA, Simon et al. analyzed the level of B7-H4 protein in over 2500 serum samples, ascites fluids and tissue lysates. They found high level of B7-H4 protein in ovarian cancer tissue lysates, but no typical 
elevation in patients with benign diseases ${ }^{30}$. In early-stage patients, the combination of B7-H4 and CA-125 identified $65 \%$ patients as positive ${ }^{31}$.

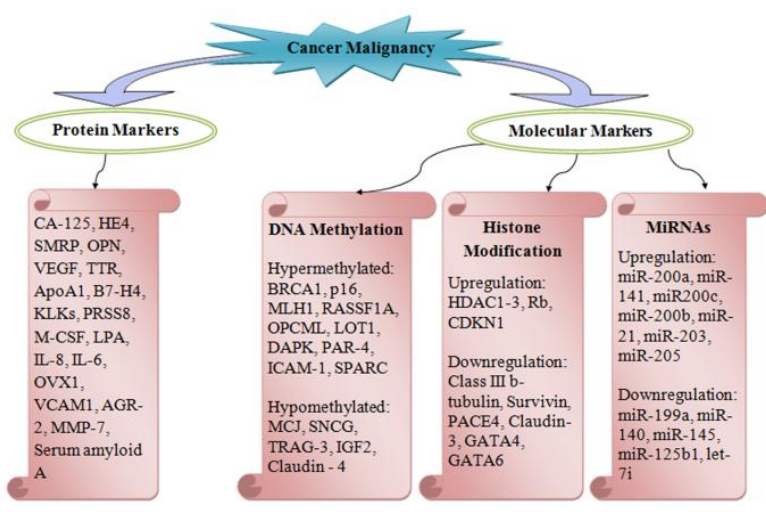

Figure 1: Potential biomarkers (protein, DNA and

RNA) in ovarian cancer diagnosis

\section{Osteopontin}

Osteopontin (OPN) is a secreted extracellular matrix glycoprotein, synthesized by vascular endothelial cells and osteoblasts. It is involved in numerous physiological and pathological processes, including wound healing, inflammation, the immune response, tumorigenesis as well as bone remodelling. OPN can also inhibit apoptosis. OPN is a useful biomarker in diagnosis of ovarian cancer with an overall sensitivity of $66 \%$ at $88 \%$ specificity $^{32}$. Kim et al. showed that the diagnostic sensitivity of OPN was lower in earlier than advanced disease (0.80 vs. 0.85$)$ suggesting that OPN level increases as the disease advances ${ }^{33}$. Using osteopontin in combination with leptin, prolactin and insulin-like growth factor-II (IGF-II), Mor et al. reported 95\% sensitivity at 95\% specificity accurately distinguishing between normal and EOC patients, including stage I and $\mathrm{II}^{34}$. A specificity of $99.4 \%$ (95.3\% sensitivity) was achieved with the addition of macrophage inhibitory factor (MIF) and CA-125 to this panel ${ }^{35}$. Similar to mesothelin, a fragment of osteopontin can be detected in the urine of ovarian cancer patients ${ }^{36}$.

\section{Kallikreins (KLKs)}

Kallikreins are low molecular mass serine proteases, localized on chromosome 19q13.4 that promote cancer cell growth, angiogenesis, invasion and metastasis. Among the 15 family members, 12 KLKs are overexpressed in ovarian cancer at the mRNA and/or protein level ${ }^{37}$.
Elevated levels of both KLK $4^{38}$ and KLK $5^{39}$ have been found to be associated with aggressive cancer. KLK 4 and KLK 9 with higher expression of KLK 5 correlate with poor prognosis. A combination of KLK6 and CA-125 significantly increased the sensitivity of each of the biomarkers (72\% sensitivity for all patients) at $90 \%$ specificity, but was not effective in screening the disease at early stage ${ }^{40}$. However, the extensive and exclusive sialylation of KLK6 from malignant ovarian cells suggests that sialylated KLK6 could serve as a novel biomarker for early detection ${ }^{41}$. Overexpression of KLK6 and KLK7 mRNA was specific to serous and papillary serous subtypes. Therefore, decreasing incidences of high "false negative" rates were found in the same patients with the common biomarkers HE4 and CA-125 ${ }^{42}$. Elevated level of KLK 10 were seen in CA-125 negative ovarian cancer patients at $90 \%$ specificity while on combining both markers a $21 \%$ increase in sensitivity was seen $(90 \% \text { specificity })^{43}$. Additionally, KLK 11 was found to be elevated in $70 \%$ of ovarian cancer sera at a specificity of $95 \%$ and that women with hK11-positive tumors have longer progression-free survival and overall survival $^{44}$.

\section{Vascular Endothelial Growth Factor (VEGF)}

VEGF is a glycosylated angiogenesis mediator involved in tumor progression, peritoneal metastasis and accumulation of ascites in ovarian cancer $^{45}$. The high VEGF level is independently associated with shorter disease-free survival and overall survival. Angiogenesis promoted by VEGF is a continuous process, independent of clinical advancement of the disease ${ }^{46}$. VEGF has been shown to be elevated in $81 \%$ CA-125 deficient ovarian cancer cases ${ }^{47}$. A combination of IL-6, IL8, VEGF, EGF, and CA-125 studied using LabMap technology resulted in $84 \%$ sensitivity $(95 \%$ specificity) proposing that using serum cytokines and CA-125 may be a promising approach for ovarian cancer detection ${ }^{48}$. Keeping the specificity of $100 \%$ for each marker, the addition of VEGF to CA-125 increased the sensitivity from 60 to $73.3 \%$ of early detection. When specificity of VEGF was decreased to $96.7 \%$ keeping the same CA-125 cutoff $(35 \mathrm{U} / \mathrm{ml})$, the sensitivity increased to $80 \%$ for stage $\mathrm{I} / \mathrm{II}$ that could accurately distinguish neoplasms from ovarian cyst ${ }^{49}$. The combination of VEGF with CA-125 and HE4 increased the diagnostic sensitivity up to $84 \%$ in stage I thus 
enabling improved early detection of this disease in contrast to either marker alone ${ }^{50}$.

\section{Prostasin}

Human prostasin (PRSS8), expressed in epithelial cells, is a trypsin-like proteinase $(40 \mathrm{KDa})$ localized on chromosome $16 \mathrm{p} 11.2$ that was identified to be overexpressed in ovarian cancer using microarray technology. Costa et al. also confirmed the increased level of associated mRNA through Real-Time PCR. Significantly higher level of prostasin was detected in the stage $\mathrm{II}^{51}$. Mok et al. obtained a sensitivity of $64.9 \%$ for CA- 125 and $51.4 \%$ for prostasin when specificity was kept at $94 \%$ for prostasin. When sera from 37 case patients were compared with control, the combination of CA-125 and prostasin gave a sensitivity of $92 \%$ at $94 \%$ specificity for detecting ovarian cancer $^{52}$. Recently, Yan et al. identified prostasin as a potential target for treating/repressing some ovarian tumors. Their studies show that forced overexpression of prostasin greatly reduces cancer cell survival, resulting in $99 \%$ cell death in a drug-resistant cell line partially reversing chemoresistance ${ }^{53}$.

\section{Methylated DNA Sequences}

Methylated DNA sequences represent potential biomarkers for diagnosis, staging, prognosis (i.e. prognostic biomarkers), and monitoring of response to therapy (predictive biomarkers) ${ }^{54,55}$. DNA methylation biomarkers hold a number of advantages over other biomarker types, such as proteins, gene expression, and DNA mutations, including their stability, ability to be amplified (thus greatly enhancing detection sensitivity), relatively low cost of assessment, and restriction to limited regions of DNA (CpG islands) ${ }^{55}$.

The occurrence rate of ovarian cancer is 5.7 per 100,000 women and it affects $5.4 \%$ of all women cancer patients in India. It is likely that DNA methylation analyses of resected ovarian tumors will be used to tailor the individual treatment, similar to recently discovered predictive markers in stage I non-small-cell lung cancer ${ }^{56}$. Ovarian cancer progression is well characterized by a number of combinatorial epigenetic aberrations distinct to this malignancy. A number of genes, including the classical tumor suppressors BRCA1 (breast cancer susceptibility gene-1) ${ }^{57}$, p16, and $\mathrm{MLH}^{58}$ as well as putative tumor suppressors (RASSF1A and OPCMLI) $^{57}$, cell adhesion (ICAM-1 and CDH1) ${ }^{59}$ and proapoptotic (LOT1,
DAPK, TMS1/ASC, and PAR-4) ${ }^{60}$ are hypermethylated and down-regulated in ovarian cancer. A newly identified gene, HSulf-1, encoding an arylsulfatase that acts on cell surface heparin sulfate proteoglycans and inhibits growth factor signaling and angiogenesis ${ }^{61}$ was found methylated in over $50 \%$ of ovarian tumors and cell lines. Tumor-specific methylation of at least one of a panel of six tumor suppressor genes (BRCA1, RASSF1A, APC, p14ARF, p16INK4a, and DAPK could be detected in serum of ovarian cancer patients with $100 \%$ specificity and $82 \%$ sensitivity ${ }^{57}$ by MSP-PCR. Hypermethylation was observed across histological cell types, grades, and stages. In contrast, no methylation was observed in non-neoplastic tissue, peritoneal fluid, or serum from 40 control women. A disadvantage of methylation-specific PCR is that only the few $\mathrm{CpG}$ sites that are situated within the template sequence to which the primers bind can be investigated for a given primer pair. At low temperatures, methylation-specific PCR lacks sensitivity, only amplifying target DNA when it is present at $90 \%$ of the total DNA. Among these BRCA1, RASSF1A and DAPK are the potential targets for analyzing other $\mathrm{CpG}$ rich regions to be identified and mapped by more sensitive techniques like methylight assay in tumor, serum and normal DNA. The specificity of the assay will be checked in cyst tissue, serum and peritoneal fluid DNA from non-neoplastic ovarian disease samples and normal ovary sample. Another important study showing the analysis of DNA methylation by methylation-specific polymerase chain reaction of 7 genes, which included secreted frizzled receptor proteins 1, 2, 4, 5 (SFRP1, 2, 4, 5), SRY box 1 (SOX1), paired box gene 1 (PAX1) and LIM homeobox transcription factor 1, alpha (LMX1A) in primary tumor samples from 126 case patients, 75 with a benign tumor and 14 with borderline malignancy of an ovarian tumor, and in the serum from 26 patients with ovarian cancer. The methylation of SFRP1, SFRP2, SOX1 and LMX1A genes correlated with recurrence and overall survival of ovarian cancer patients. Combining the data for SFRP1, SFRP2 and SOX1 genes gave a relative risk for recurrence of 3.19 $(\mathrm{p}=0.013)$ in patients with at least one gene methylation, and combining the data for SFRP1, SOX1 and LMX1A gave a relative risk for cancerrelated death of $6.09(\mathrm{p}=0.010)$. The sensitivity and specificity were 73.08 and $75 \%$, respectively, when any one of SOX1, PAX1 and SFRP1 genes 
showed methylation ${ }^{62}$. Further, a microarray analysis resulted in the identification of 112 highly discriminatory loci possessing a progression-free survival prediction accuracy of $95 \%$ in ovarian cancer patients by applying SAM and PAM analysis (Significance and prediction analysis of microarray). A higher degree of $\mathrm{CpG}$ island methylation was also associated with early disease recurrence after chemotherapy ${ }^{54}$. Recently, FILIP1L (filamin A interacting protein 1-like), p150 and SALL2 P2 expression is inversely correlated with the invasive potential of ovarian cancer cell lines and clinical ovarian cancer specimens. Promoters of these genes are hypermethylated in cancer phenotypes and are down-regulated in invasive form of ovarian cancer $^{63,64}$.

A sensitive blood-based colorectal cancer screening test was developed by Warren et al. using the SEPT9 gene methylation in plasma (serum DNA) specifically detects a majority of colorectal cancers of all stages and colorectal locations ${ }^{65}$. Similarly, SHOX2 DNA methylation has been used as a biomarker for the diagnosis of lung cancer in plasma ${ }^{66}$ by Kneip et al. Prostate cancer has been correlated with methylation of Ecadherin, androgen receptor, cyclin D2, CD44, HIC1, and RASSF1 $\mathrm{A}^{67}$, while lung cancer has been linked to methylation of caspase-8, DAPK,

Table1: Commercially available tests based on DNA methylation biomarkers

\begin{tabular}{|c|c|c|c|c|c|}
\hline Biomarker & Application & Disease & Material & $\begin{array}{l}\text { Sensitivity/ } \\
\text { Specificity }(\%)\end{array}$ & Commercial test \\
\hline SEPT9 + VIM & M Early detection & $\begin{array}{l}\text { Colorectal } \\
\text { Cancer }\end{array}$ & Blood & 80-82/ 89-99 & $\begin{array}{l}\text { Epi proColon }{ }^{\circledR} \quad 2.071 \\
\text { (Epigenomics), } \\
\text { ColoVant ageTM (Quest } \\
\text { Diagnostics), Real- } \\
\text { Time mS9 (Abbott) }\end{array}$ \\
\hline SHOX2 & Early detection & Lung Cancer & Sputum & $81 / 95$ & $\begin{array}{l}\text { Epi proLung }{ }^{\circledR} \text { BL } 1.066 \\
\text { (Epigenomics) }\end{array}$ \\
\hline $\begin{array}{l}\text { GSTP1 + AP } \\
+ \text { RASSF1 }\end{array}$ & $\begin{array}{l}\text { PCConfirm negati } \\
\text { biopsy and ear } \\
\text { detection }\end{array}$ & $\begin{array}{l}\text { eProstate } \\
\text { yCancer }\end{array}$ & $\begin{array}{l}\text { Prostate } \\
\text { biopsy }\end{array}$ & $74 / 63$ & $\begin{array}{l}\text { Confirm } \quad \text { MDx for72 } \\
\begin{array}{l}\text { Prostate } \\
\text { (MdxHealth) }\end{array}\end{array}$ \\
\hline MGMT & Predictive & Brain Cancer & Tumor & - & $\begin{array}{l}\text { PredictMDx }{ }^{\mathrm{TM}} \text { Brain73 } \\
\text { Cancer (MDxHealth) }\end{array}$ \\
\hline $\begin{array}{l}\text { TWIST2 } \\
\text { NID2 }\end{array}$ & +Predictive & $\begin{array}{l}\text { Bladder } \\
\text { Cancer }\end{array}$ & Urine & $87.9 / 99.9$ & $\begin{array}{lr}\text { CertNDx }^{\mathrm{TM}} & \text { Bladder74 } \\
\text { Cancer } & \text { Assay } \\
\text { Hematuria } & \text { Assessment } \\
\text { (Predictive Biosciences) }\end{array}$ \\
\hline
\end{tabular}

\section{MicroRNAs}

Attention has been lately focused on microRNAs as potential epigenetic markers of ovarian cancer. These are a large family of single stranded and non-protein-coding RNA molecule (18-24
MGMT, p16INK4, and RASSF1A ${ }^{68}$. Genome wide methylation results of four epithelial ovarian serous carcinoma and two normal ovarian tissues shows that out of 367 methylated $\mathrm{CpG}$ islands, 129 were marked by polycomb proteins near the TSS of their genes ${ }^{69}$. Another important study by Huang et al. on comprehensive methylation analysis of malignant ovarian tumors showed silencing of ZIC1 and ZIC4 (members of hedgehog pathway) ${ }^{70}$. Repression of these genes (ZIC1 promoter hypermethylation) correlated with increased proliferation, migration and invasion.

As several methylated genes are now correlated with various tumor types, attempts can be made to establish a "panel" of discriminative biomarkers for any one particular cancer and its specific subtypes and/or stages. In ovarian cancer particularly, methylation biomarkers could supplement the specificity of CA-125, similar to ongoing prostate cancer studies examining various prostate-specific antigen/biomarkers. In addition to tissue analysis, methylated DNA has been detected in the serum and peritoneal fluid of ovarian cancer patients.(Table1) nucleotides) that function as negative regulators of gene expression. Through the binding of these evolutionarily conserved small molecules to the 3'untranslated regions of their target mRNAs, translational repression and/or mRNA degradation 
is mediated. They regulate over $60 \%$ of all human genes and are involved in various processes including development, differentiation, metabolism, proliferation, cell cycle, inflammation and the immune system ${ }^{75}$. Reports have suggested that aberrant expression of miRs is linked to carcinogenesis in ovarian cancer where they function as both oncogenes and tumor suppressor genes. Previously, miRNA expression profiling by Iorio et al. has stated the differential expression of miRNAs between ovarian cancer tissues/cell lines and normal tissues. MiR-141, miR-200a, miR200b, and miR-200c were most significantly overexpressed while miR-199a, miR-140, miR145 , and miR-125b1 were most underexpressed in the cancer samples ${ }^{76}$. They also observed different miRNA signatures in different ovarian carcinoma histotypes (serous, endometrioid, clear cell, and mucinous). Recently, miR-494 was found to be decreased in OC tissues and cell lines. Additional investigation indicated that overexpression of miR-494 could suppress ovarian cancer cell proliferation by inducing apoptosis via targeting FGFR ${ }^{77}$. An increase in the level of miR-182 in EOC has been linked with significantly shorter overall survival $^{78}$.
Circulating microRNAs have also been identified in serum, exosomes and whole blood that provide the advantages of minimally invasive test for detection of early cancer. In the exosomes isolated from the serum of ovarian cancer, Taylor et al. found elevated expression of miR-21, -141, -200a, $-200 b,-200 c,-203,-205$, and -214 when compared to patients with benign disease ${ }^{79}$. Similar studies by Resnick et al., Chung et al., Suryawanshi et al. and many more have identified several miRNAs as significant biomarker of ovarian cancer. Recently, Zheng et al. showed that plasma miR-205 and let$7 \mathrm{f}$ could be used as biomarkers for ovarian cancer detection, especially in patients with stage I disease $^{80}$. Epigenetic silencing is considered as the prime suspect of deregulated expression of microRNAs in ovarian cancer. Decreased expression of let- $7 \mathrm{a}-3^{81}$, miR-34a, miR-34b/c ${ }^{82}$ and miR-130 $b^{83}$ has been correlated with hypermethylation of their respective genes. Furthermore, downregulation of miR-9-1 $1^{84}$, let$7 \mathrm{e}^{85}$ and miR-199-5 $\mathrm{p}^{86}$ due to hypermethylation, is found to be associated with the development of chemoresistance in ovarian cancer. However, further inspection is necessary to establish miRNA as novel molecular markers for ovarian cancer.

(Table2)

Table 2: Potential diagnostic/prognostic microRNAs for ovarian cancer.

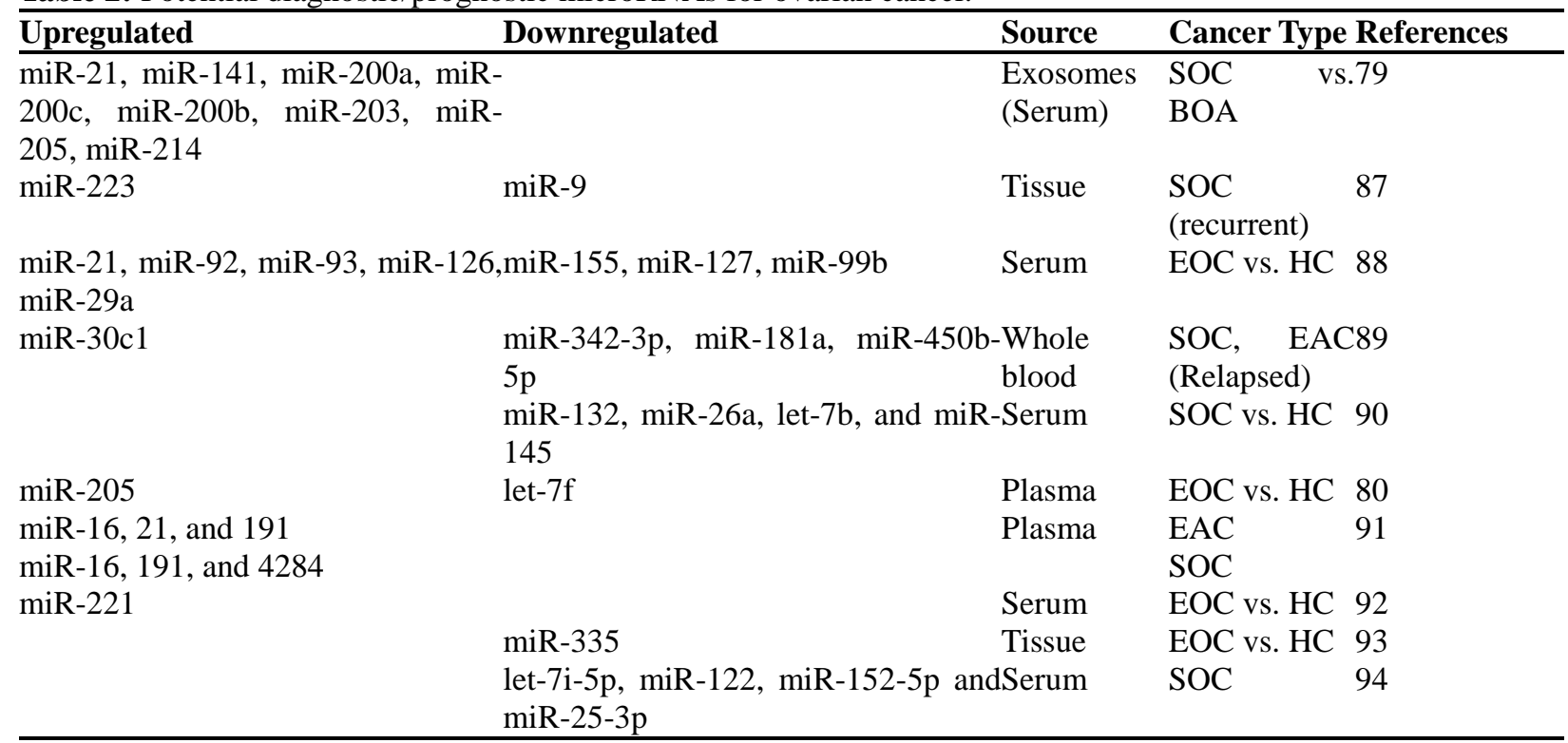

SOC: Serous ovarian cancer; BOA: Benign ovarian adenoma; HC: Healthy control; EOC: Epithelial ovarian cancer; EAC: endometrioid adenocarcinoma.

\section{APTAMERS TARGETING TUMOR- SPECIFIC BIOMARKERS: A NEW HOPE FOR OVARIAN CANCER}

Aptamers, first reported in 1990 by Ellington and Gold, are single-stranded DNA or RNA oligonucleotides (12-30 bases) or more recently peptides. These three-dimensional in vivo structures are highly specific and possess high 
affinity to their target molecules. Since their discovery, numerous high affinity aptamers have been selected for targeting a wide range of molecules, including proteins, amino acids, metal ions, and even whole cells such as viruses. Aptamers are generated in a process named Systematic Evolution of Ligand by Exponential Enrichment (SELEX) or Cell-SELEX. The latter targeting a whole live cell instead of isolated molecules, ensuring that the developed aptamers are highly suitable for biological applications. Moreover, the quantity or types of targeted proteins on the cell surface need not to be known thus offering a great convenience and simplicity in the selection process. Furthermore, using cellSELEX technology specific type of cancer cells, but not the normal or other cells can be targeted. This aids discrimination among closely related cell types or even within the same cell under different conditions. Aptamers or 'chemical antibodies' offer more advantages as compared to the antibodies. The fact that they can be selected invitro for any given targets and they can be synthesized with high reproducibility and purity in large quantities overcomes the limitations of using antibodies. The aptamers selection process does not require any animals to be hurt. Not only can they be modified with functional groups while retaining their affinity, they are very stable and recover their active conformation even after thermal denaturation. Moreover, they are less immunogenic, have better tissue penetration and show faster clearance. Owing to these unique characteristics, aptamers have shown potential applications in bioanalysis, biomedicine and most importantly in cancer-related research, including cancer biomarker discovery, imaging, diagnosis and therapy ${ }^{95}$.

The main problem with cancer is the lack of sensitive and specific methods for its discovery in the early stages. Aptamers have been extensively studied for diagnosis and/or treatment of lung, liver, breast, ovarian, brain, colorectal and pancreatic cancers, as well as for identification and characterization of cancer stem cells. Cancerrelated proteins such as platelet-derived growth factor (PDGF), vascular-endothelial growth factor (VEGF), human epidermal growth factor receptor 3 (HER3), tenascin-C, nuclear factor kappa-lightchain-enhancer (NFKB) of activated B cells, and prostate-specific membrane antigen (PMSA) have been investigated. Different aptamer substances are under various phases of clinical and preclinical trials $^{95,96}$.

Zhu et al. developed a sandwich electrochemical aptasensor for the detection of HER2 and HER2overexpressing breast cancer cells. Using the mono-antibody of HER2 (anti-HER2) and a bioconjugate of hydrazine-AuNP (Gold Nanoparticle)-Aptamer (Hyd-AuNP-Apt), target molecules and cells can be quantitatively measured using stripping voltammetry. Using this technique, the SK-BR-3 breast cancer cells could be detected in human sera as low as 26 cells $/ \mathrm{ml}^{97}$. Mucin1 (MUC1), a glycoprotein expressed on most epithelial cell surfaces, was discovered as an important tumor marker in the diagnosis, screening and prognosis of ovarian cancer. $\mathrm{Ma}$ et al. developed an aptamers-based electrochemical biosensor for quantitative determination of MUC1 by modifying the anti-MUC1 DNA aptamers on the surface of gold electrode. These DNA single strands formed a hairpin structure without MUC1 facilitating electron transfer between methylene blue (MB) and the gold electrode. Upon MUC1 binding, this hairpin conformation no longer persists, hence displacing MB away from the gold electrode hindering the electron transfer. The marker can thus be detected up to $50 \mathrm{mM}$ with a dynamic response range of up to $1.5 \mu \mathrm{M}$ which is far better than ELISA ${ }^{98}$.

In a recent study, Cha et al. developed a biosensor for early diagnosis of prostate cancer using guanine (G)-rich DNA aptamers-conjugated 6carboxyfluorescein (6-FAM) that can rapidly capture Prostate-specific antigen (PSA) in human serum. Free G-rich DNA aptamer-conjugated 6FAM emits bright light in a chemiluminescence reaction based on the principle of chemiluminescent resonance energy transfer (CRET). PSA shows strong interference in this reaction. Due to the different properties of G-rich DNA aptamer-conjugated 6-FAM in the absence and presence of PSA in guanine chemiluminescence reaction, even trace levels of PSA in human serum can be quantified within 30 min without time-consuming and complicated procedures. The limit of detection (LOD) of this biosensor having a wide linear dynamic range $(1.9-125 \mathrm{ng} / \mathrm{ml})$ was $1.0 \mathrm{ng} / \mathrm{ml}^{99}$. Similar findings clearly demonstrate that aptamer-based approaches can also potentially target ovarian cancer.

Ovarian cancer is a malignancy with poor survival rates and no single method has been approved for its early diagnosis till date. In this scenario, 
discovery and validation of new ovarian cancer biomarkers using aptamers provide a hope to enable early detection. Van Simaeys et al. selected a total of 13 aptamers for two model ovarian cancer cell lines: the ovarian clear cell carcinoma (OCCA) cell line TOV-21G (10 aptamers) and ovarian serous adenocarcinoma line CAOV-3 (3 aptamers) and further investigated the cell surface targets of these aptamers and their binding characteristics. A cervical cancer cell line HeLa was taken in counter selection to ensure the aptamers could distinguish ovarian cancer from cervical cancer. The aptTOV aptamers did not bind to a cancer of same etiology (CAOV-3) and also not to HeLa, but showed binding to cancer cell lines from different non-related cancers ${ }^{100}$. Aptamers can thus provide more insight into the pathology of ovarian cancer and also lead to the identification of biomarkers related to different cancers. Eaton et al. used capillary electrophoresis (CE) for identifying DNA aptamers with an affinity for ovarian cancer biomarker HE4. The selected DNA aptamers were subjected to high throughput sequencing on the Illumina platform. Further characterization was done by fluorescent anisotropy as well as affinity probe capillary electrophoresis for specific binding of each aptamer candidate for the positive selection of protein target ${ }^{101}$. Recently, an integrated microfluidic system was successfully developed by Hung et al. offering an automatic, highthroughput screening of multiple cell lines for selecting aptamer-based biomarkers for ovarian cancer. The system was capable of performing cell-SELEX process that required only five rounds of aptamer selection as compared to the conventional SELEX process (22 rounds). Three out of the 13 aptamers successfully screened for ovarian cancer cells, showed high affinity towards target cells with dissociation constants of $1.8 \mathrm{nM}$, $8.3 \mathrm{nM}$, and $1.3 \mathrm{nM}^{102}$. The specificity of the selected aptamers was further verified against multiple cancer cell lines. The results demonstrate that this system can be utilized for early diagnosis of ovarian cancer as well as targeted therapy monitoring in the near future.

Aptamers have also been utilized in identifying novel biomarkers of different cancers. Van Simaeys et al. used aptamer TOV6 selected by cell-SELEX from their previous study to identify and further validate the protein target of this aptamer. After binding of TOV6 to its cognate target on the cell surface membrane, the
TOV6/target interaction was fixed with formaldehyde to enable subsequent protein identification by mass spectrometry (MS). After the extraction and recovery of the protein-aptamer hybrid from the cell lysate, the protein was identified as stress-induced phosphoprotein 1 (STIP1) by $\mathrm{MS}^{103}$. The identity of the target was further confirmed through siRNA silencing and antibody binding. Using Boyden chambers further validated the role of STIP1 in cell invasion and that TOV6 is a potent inhibitor in this oncological process. By identifying the target of TOV6, a blocking effect in the metastatic process of TOV$21 \mathrm{G}$ could be identified. Cell-SELEX yield ligands that most likely bind to the overexpressed cell surface proteins on cancer cells, while subtracting the ligands to more general cell surface proteins by negative selection.

Many investigations are going on to identify aptamers which are ovarian tumor-specific for early diagnosis of ovarian cancer, which will help in reducing mortality as well as improve current long-term survival rates.

\section{REFERENCES}

1. Chen VW, Ruiz B, Killeen JL, Coté TR, Wu XC, Correa CN. Pathology and classification of ovarian tumors. Cancer. 2003; 97(10): 2631-2642.

2. Bast RC. Early detection of ovarian cancer: new technologies in pursuit of a disease that is neither common nor rare. Trans Am Clin Climatol Assoc. 2004; 115: 233-248.

3. Seol HJ, Ki KD, Lee JM. Epidemiologic characteristics of cervical cancer in Korean women. J Gynecol Oncol. 2014; 25(1): 70-74. doi:10.3802/jgo.2014.25.1.70.

4. Woolas RP, Xu FJ, Jacobs IJ, Yu YH, Daly L, Berchuck A et al. Elevation of multiple serum markers in patients with stage I ovarian cancer. $J$ Natl Cancer Inst. 1993; 85(21): 1748-1751.

5. Sarojini S, Tamir A, Lim H, Li S, Zhang S, Goy A, et al. Early detection biomarkers for ovarian cancer. J Oncol. 2012. doi:10.1155/2012/709049.

6. Cohen JG, White M, Cruz A, Farias-Eisner R. In 2014, can we do better than CA125 in the early detection of ovarian cancer? World J Biol Chem. 2014; 5(3): 286-300. doi:10.4331/wjbc.v5.i3.286.

7. Moore RG, Brown AK, Miller MC, Skates S, Allard WJ, Verch T, et al. The use of multiple novel tumor biomarkers for the detection of ovarian carcinoma in patients with a pelvic mass. Gynecol Oncol. 2008; 108(2): 402-408. Epub 2007 Dec 3. 
8. Azzam AZ, Hashad DI, Kamel NA. Evaluation of HE4 as an extrabiomarker to CA125 to improve detection of ovarian carcinoma: is it time for a step forward? Arch Gynecol Obstet. 2013; 288(1): 167172. doi: 10.1007/s00404-013-2722-2.

9. Kristjansdottir B, Levan K, Partheen K, Sundfeldt K. Diagnostic performance of the biomarkers HE4 and CA125 in type I and type II epithelial ovarian cancer. Gynecol Oncol. 2013; 131(1): 52-58. doi: 10.1016/j.ygyno.2013.07.094.

10. Hellstrom I, Heagerty PJ, Swisher EM, Liu P, Jaffar J, Agnew K, et al. Detection of the HE4 protein in urine as a biomarker for ovarian neoplasms. Cancer Lett. 2010; 296(1): 43-48. doi: 10.1016/j.canlet.2010.03.013.

11. Muller CY. Doctor, should I get this new ovarian cancer test-OVA1? Obstet Gynecol. 2010; 116: 246-247. doi: 10.1097/AOG.0b013e3181e934ba.

12. Bast RC Jr, Skates S, Lokshin A, Moore RG. Differential diagnosis of a pelvic mass: improved algorithms and novel biomarkers. Int J Gynecol Cancer. 2012; 22(1): S5-8. doi: 10.1097/IGC.0b013e318251c97d.

13. Havrilesky LJ, Whitehead CM, Rubatt JM, Cheek RL, Groelke J, He Q, et al. Evaluation of biomarker panels for early stage ovarian cancer detection and monitoring for disease recurrence. Gynecol Oncol. 2008; 110(3): 374-382. doi: 10.1016/j.ygyno.2008.04.041.

14. Yurkovetsky Z, Skates S, Lomakin A, Nolen B, Pulsipher T, Modugno F, et al. Development of a multimarker assay for early detection of ovarian cancer. J Clin Oncol. 2010; 28(13): 2159-2166. doi: 10.1200/JCO.2008.19.2484.

15. Simmons AR, Clarke CH, Badgwell DB, Lu Z, Sokoll LJ, Lu KH, et al. Validation of a biomarker panel and longitudinal biomarker performance for early detection of ovarian cancer. Int J Gynecol Cancer. 2016; 26(6): 1070-1077.

16. McIntosh MW, Drescher C, Karlan B, Scholler $\mathrm{N}$, Urban N, Hellstrom KE, et al. Combining CA 125 and SMR serum markers for diagnosis and early detection of ovarian carcinoma. Gynecol Oncol. 2004; 95(1): 9-15.

17. Obulhasim G, Fujii H, Matsumoto $T$, Yasen M, Abe M, Matsuoka S, et al. Mesothelin gene expression and promoter methylation/hypomethylation in gynecological tumors. Eur J Gynaecol Oncol. 2010; 31(1): 63-71.

18. Tang Z, Qian M, Ho M. The role of mesothelin in tumor progression and targeted therapy. Anticancer Agents Med Chem. 2013; 13(2): 276280.

19. Badgwell D, Lu Z, Cole L, Fritsche H, Atkinson EN, Somers E, et al. Urinary mesothelin provides greater sensitivity for early stage ovarian cancer than serum mesothelin, urinary $\mathrm{hCG}$ free beta subunit and urinary hCG beta core fragment. Gynecol Oncol. 2007; 106(3): 490-497. Epub 2007 May 25.

20. Zhang Z, Bast RC Jr, Yu Y, Li J, Sokoll LJ, Rai AJ, et al. Three biomarkers identified from serum proteomic analysis for the detection of early stage ovarian cancer. Cancer Res. 2004; 64(16): 58825890.

21. Cramer DW, Bast RC Jr, Berg CD, Diamandis EP, Godwin AK, Hartge P, et al. Ovarian cancer biomarker performance in prostate, lung, colorectal, and ovarian cancer screening trial specimens. Cancer Prev Res (Phila). 2011; 4(3): 365-374. doi: 10.1158/1940-6207.CAPR-10-0195.

22. Nosov V, Su F, Amneus M, Birrer M, Robins $\mathrm{T}$, Kotlerman J, et al. Validation of serum biomarkers for detection of early-stage ovarian cancer. Am J Obstet Gynecol. 2009; 200(6): 639. doi: 10.1016/j.ajog.2008.12.042.

23. Clarke CH, Yip C, Badgwell D, Fung ET, Coombes KR, Zhang Z, et al. Proteomic biomarkers apolipoprotein A1, truncated transthyretin and connective tissue activating protein III enhance the sensitivity of CA125 for detecting early stage epithelial ovarian cancer. Gynecol Oncol. 2011; 122(3): 548-553. doi: 10.1016/j.ygyno.2011.06.002.

24. Gadomska H, Grzechocińska B, Janecki J, Nowicka G, Powolny M, Marianowski L. Serum lipids concentration in women with benign and malignant ovarian tumours. Eur J Obstet Gynecol Reprod Biol. 2005; 120(1): 87-90.

25. Kim YW, Bae SM, Lim H, Kim YJ, Ahn WS. Development of multiplexed bead-based immunoassays for the detection of early stage ovarian cancer using a combination of serum biomarkers. PloS One. 2012; 7(9): e44960. doi: 10.1371/journal.pone.0044960.

26. Pal MK, Rashid M, Bisht M. Multiplexed magnetic nanoparticle-antibody conjugates (MNPsABS) based prognostic detection of ovarian cancer biomarkers, CA-125, $\beta-2 \mathrm{M}$ and ApoA1 using fluorescence spectroscopy with comparison of surface plasmon resonance (SPR) analysis. Biosens Bioelectron. 2015; 73: 146-152. doi: 10.1016/j.bios.2015.05.051.

27. Fassl S, Leisser C, Huettenbrenner S, Maier S, Rosenberger G, Strasser S, et al. Transferrin ensures survival of ovarian carcinoma cells when apoptosis is induced by TNFalpha, FasL, TRAIL, or Myc. Oncogene. 2003; 22(51): 8343-8355.

28. Ahmed N, Oliva KT, Barker G, Hoffmann P, Reeve S, Smith IA, et al. Proteomic tracking of serum protein isoforms as screening biomarkers of 
ovarian cancer. Proteomics. 2005; 5(17): 46254636.

29. Su F, Lang J, Kumar A, Ng C, Hsieh B, Suchard MA, et al. Validation of candidate serum ovarian cancer biomarkers for early detection. Biomark Insights. 2007; 2: 369-375.

30. Simon I, Zhuo S, Corral L, Diamandis EP, Sarno MJ, Wolfert RL, et al. B7-H4 is a novel membranebound protein and a candidate serum and tissue biomarker for ovarian cancer. Cancer Res. 2006; 66(3): 1570-1575.

31. Simon I, Katsaros D, Rigault de la Longrais I, Massobrio M, Scorilas A, Kim NW, et al. B7-H4 is over-expressed in early-stage ovarian cancer and is independent of CA125 expression. Gynecol Oncol. 2007; 106(2): 334-341. Epub 2007 May 11.

32. Hu ZD, Wei TT, Yang M, Ma N, Tang QQ, Qin $\mathrm{BD}$ et al. Diagnostic value of osteopontin in ovarian cancer: A meta-analysis and systematic review. PLoS One. 2015; 10(5): e0126444. doi: 10.1371/journal.pone.0126444.

33. Kim JH, Skates SJ, Uede T, Wong KK, Schorge JO, Feltmate CM, et al. Osteopontin as a potential diagnostic biomarker for ovarian cancer. JAMA. 2002; 287(13): 1671-1679.

34. Mor G, Visintin I, Lai Y, Zhao H, Schwartz $\mathrm{P}$, Rutherford T, et al. Serum protein markers for early detection of ovarian cancer. Proc Natl Acad Sci USA. 2005; 102(21): 7677-7682. Epub 2005 May 12.

35. Kim K, Visintin I, Alvero AB, Mor G. Development and validation of a protein based signature for the detection of ovarian cancer. Clin Lab Med. 2009; 29(1): 47-55. doi:10.1016/j.cll.2009.02.001.

36. Ye B, Skates S, Mok SC, Horick NK, Rosenberg $\mathrm{HF}$, Vitonis A, et al. Proteomic-based discovery and characterization of glycosylated eosinophil-derived neurotoxin and $\mathrm{COOH}$-terminal osteopontin fragments for ovarian cancer in urine. Clin Cancer Res. 2006; 12(2): 432-441.

37. Borgoño CA, Diamandis EP. The emerging roles of human tissue kallikreins in cancer. Nat Rev Cancer. 2004; 4(11): 876-890.

38. Obiezu CV, Diamandis EP. Human tissue kallikrein gene family: applications in cancer. Cancer Lett. 2005; 224(1):1-22.

39. Dong Y, Kaushal A, Brattsand M, Nicklin J, Clements JA. Differential splicing of KLK5 and KLK7 in epithelial ovarian cancer produces novel variants with potential as cancer biomarkers. Clin Cancer Res. 2003; 9(5): 1710-1720.

40. Diamandis EP, Scorilas A, Fracchioli S, Van Gramberen M, De Bruijn H, Henrik A, et al. Human kallikrein 6 (hK6): a new potential serum biomarker for diagnosis and prognosis of ovarian carcinoma. $J$ Clin Oncol. 2003; 21(6): 1035-1043.

41. Kuzmanov U, Jiang N, Smith CR, Soosaipillai A, Diamandis EP. Differential N-glycosylation of kallikrein 6 derived from ovarian cancer cells or the central nervous system. Mol Cell Proteomics. 2009; 8(4): 791-798. doi: 10.1074/mcp.M800516MCP200.

42. Tamir A, Jag U, Sarojini S, Schindewolf C, Tanaka T, Gharbaran R, et al. Kallikrein family proteases KLK6 and KLK7 are potential early detection and diagnostic biomarkers for serous and papillary serous ovarian cancer subtypes. J Ovarian Res. 2014; 7:109. doi: 10.1186/s13048-014-0109-z.

43. Luo LY, Katsaros D, Scorilas A, Fracchioli $\mathrm{S}$, Bellino R, van Gramberen $\mathrm{M}$, et al. The serum concentration of human kallikrein 10 represents a novel biomarker for ovarian cancer diagnosis and prognosis. Cancer Res. 2003; 63(4): 807-811.

44. Diamandis EP, Borgoño CA, Scorilas A, Harbeck N, Dorn J, Schmitt M. Human kallikrein 11: an indicator of favorable prognosis in ovarian cancer patients. Clin Biochem. 2004; 37(9): 823829.

45. Hefler LA, Zeillinger R, Grimm C, Sood AK, Cheng WF, Gadducci A, et al. Preoperative serum vascular endothelial growth factor as a prognostic parameter in ovarian cancer. Gynecol Oncol. 2006; 103(2): 512-517. Epub 2006 Jun 5.

46. Harlozinska A, Sedlaczek P, Kulpa J, Grybos M, Wójcik E, Van Dalen A, et al. Vascular endothelial growth factor (VEGF) concentration in sera and tumor effusions from patients with ovarian carcinoma. Anticancer Res. 2004; 24(2C): 1149 1157.

47. Rosen DG, Wang L, Atkinson JN, Yu Y, Lu $\mathrm{KH}$, Diamandis EP, et al. Potential markers that complement expression of CA125 in epithelial ovarian cancer. Gynecol Oncol. 2005; 99(2): 267277. Epub 2005 Aug 2.

48. Gorelik E, Landsittel DP, Marrangoni AM, Modugno F, Velikokhatnaya L, Winans MT, et al. Multiplexed immunobead-based cytokine profiling for early detection of ovarian cancer. Cancer Epidemiol Biomarkers Prev. 2005; 14(4): 981-987.

49. Robati M, Ghaderi A, Mehraban M, Shafizad A, Nasrolahi H, Mohammadianpanah M. Vascular endothelial growth factor (VEGF) improves the sensitivity of CA125 for differentiation of epithelial ovarian cancers from ovarian cysts. Arch Gynecol Obstet. 2013; 288(4): 859-865. doi: 10.1007/s00404-013-2819-7.

50. Lawicki S, Będkowska GE, Gacuta-Szumarska E, Szmitkowski M. The plasma concentration of VEGF, HE4 and CA125 as a new biomarkers panel 
in different stages and sub-types of epithelial ovarian tumors. J Ovarian Res. 2013; 6(1): 45. doi: 10.1186/1757-2215-6-45.

51. Costa FP, Batista EL Jr, Zelmanowicz A, Svedman C, Devenz G, Alves S, et al. Prostasin, a potential tumor marker in ovarian cancer--a pilot study. Clinics (Sao Paulo). 2009; 64(7): 641-644. doi: 10.1590/S1807-59322009000700006.

52. Mok SC, Chao J, Skates S, Wong K, Yiu GK, Muto MG, et al. Prostasin, a potential serum marker for ovarian cancer: identification through microarray technology. J Natl Cancer Inst. 2001; 93(19): 1458-1464.

53. Yan BX, Ma JX, Zhang J, Guo Y, Mueller MD, Remick SC, et al. Prostasin may contribute to chemoresistance, repress cancer cells in ovarian cancer, and is involved in the signaling pathways of CASP/PAK2-p34/actin. Cell Death Dis. 2014; 5: 523. doi: 10.1038/cddis.2013.523.

54. Wei SH, Balch C, Paik HH, Kim YS, Baldwin RL, Liyanarachchi S, et al. Prognostic DNA methylation biomarkers in ovarian cancer. Clin Cancer Res. 2006; 12(9): 2788-2794.

55. Cho KR, Shih IeM. Ovarian cancer. Annu Rev Pathol. 2009; 4: 287-313. doi: 10.1146/annurev.pathol.4.110807.092246.

56. Esteller M, Sanchez-Cespedes M, Rosell R, Sidransky D, Baylin SB, Herman JG. Detection of aberrant promoter hypermethylation of tumor suppressor genes in serum DNA from non-small cell lung cancer patients. Cancer Res. 1999; 59(1): 6770.

57. Ibanez de Caceres I, Battagli C, Esteller M, Herman JG, Dulaimi E, Edelson MI, et al. Tumor cell-specific BRCA1 and RASSF1A hypermethylation in serum, plasma, and peritoneal fluid from ovarian cancer patients. Cancer Res. 2004; 64(18): 6476-6481.

58. Brown R, Hirst GL, Gallagher WM, Mcllwrath AJ, Margison GP, van der Zee AG, et al. hMLH1 expression and cellular responses of ovarian tumour cells to treatment with cytotoxic anticancer agents. Oncogene. 1997; 15(1): 45-52.

59. Arnold JM, Cummings M, Purdie D, ChenevixTrench G. Reduced expression of intercellular adhesion molecule-1 in ovarian adenocarcinomas. Br J Cancer. 2001; 85: 1351-1358.

60. Cvetkovic D, Pisarcik D, Lee C, Hamilton TC, Abdollahi A. Altered expression and loss of heterozygosity of the LOT1 gene in ovarian cancer. Gynecol Oncol. 2004; 95(3): 449-455.

61. Backen AC, Cole CL, Lau SC, Clamp AR, McVey R, Gallagher JT, et al. Heparan sulphate synthetic and editing enzymes in ovarian cancer. $\mathrm{Br}$ J Cancer. 2007; 96(10): 1544-1548. Epub 2007 Apr 17.
62. Su HY, Lai HC, Lin YW, Chou YC, Liu CY, Yu $\mathrm{MH}$. An epigenetic marker panel for screening and prognostic prediction of ovarian cancer. Int $J$ Cancer. 2009; 124(2): 387-393. doi: 10.1002/ijc.23957.

63. Burton ER, Gaffar A, Lee SJ, Adeshuko F, Whitney KD, Chung JY, et al. Downregulation of Filamin A interacting protein 1-like is associated with promoter methylation and induces an invasive phenotype in ovarian cancer. Mol Cancer Res. 2011; 9(8): 1126-1138. doi: 10.1158/1541-7786.MCR-110162.

64. Sung CK, Li D, Andrews E, Drapkin R, Benjamin T. Promoter methylation of the SALL2 tumor suppressor gene in ovarian cancers. Mol Oncol. 2013; 7(3): 419-427. doi: 10.1016/j.molonc.2012.11.005.

65. Warren JD, Xiong W, Bunker AM, Vaughn CP, Furtado LV, Roberts WL, et al. Septin 9 methylated DNA is a sensitive and specific blood test for colorectal cancer. BMC Med. 2011; 9: 133.

66. Kneip C, Schmidt B, Seegebarth A, Weickmann $\mathrm{S}$, Fleischhacker M, Liebenberg V, et al. SHOX2 DNA methylation is a biomarker for the diagnosis of lung cancer in plasma. J Thorac Oncol. 2011; 6(10): 1632-1638. doi: 10.1097/JTO.0b013e318220ef9a.

67. Maruyama R, Toyooka S, Toyooka KO, Virmani AK, Zöchbauer-Müller S, Farinas AJ, et al. Aberrant promoter methylation profile of prostate cancers and its relationship to clinicopathological features. Clin Cancer Res. 2002; 8(2): 514-519.

68. Belinsky SA. Gene-promoter hypermethylation as a biomarker in lung cancer. Nat Rev Cancer. 2004; 4(9): 707-717.

69. Michaelson-Cohen R, Keshet I, Straussman R, Hecht M, Cedar H, Beller U. Genome-wide de novo methylation in epithelial ovarian cancer. Int $J$ Gynecol Cancer. 2011; 21(2): 269-279. doi: 10.1097/IGC.0b013e31820e5cda.

70. Huang RL, Gu F, Kirma NB, Ruan J, Chen CL, Wang $\mathrm{HC}$, et al. Comprehensive methylome analysis of ovarian tumors reveals hedgehog signaling pathway regulators as prognostic DNA methylation biomarkers. Epigenetics. 2013; 8(6): 624-634. doi: 10.4161/epi.24816.

71. deVos T, Tetzner R, Model F, Weiss G, Schuster M, Distler J, et al. Circulating methylated SEPT9 DNA in plasma is a biomarker for colorectal cancer. Clin Chem. 2009; 55(7), 1337-1346. doi: 10.1373/clinchem.2008.115808.

72. Van Neste L, Bigley J, Toll A, Otto G, Clark J, Delrée P, et al. A tissue biopsy-based epigenetic multiplex PCR assay for prostate cancer detection. BMC Urol. 2012; 12: 16. doi: 10.1186/1471-249012-16. 
73. Hegi ME, Diserens AC, Gorlia T, Hamou MF, de Tribolet N, Weller $\mathrm{M}$, et al. MGMT gene silencing and benefit from temozolomide in glioblastoma. N Engl J Med. 2005; 352(10): $997-$ 1003.

74. Renard I, Joniau S, van Cleynenbreugel B, Collette C, Naômé C, Vlassenbroeck I, et al. Identification and validation of the methylated TWIST1 and NID2 genes through real-time methylation-specific polymerase chain reaction assays for the noninvasive detection of primary bladder cancer in urine samples. Eur Urol. 2010; 58(1): 96-104. doi: 10.1016/j.eururo.2009.07.041.

75. Kinose Y, Sawada K, Nakamura K, Kimura T. The role of microRNAs in ovarian cancer. Biomed Res Int. 2014; 249393. doi: 10.1155/2014/249393.

76. Iorio MV, Visone $\mathrm{R}$, Di Leva G, Donati V, Petrocca F, Casalini P, et al. MicroRNA signatures in human ovarian cancer. Cancer Res. 2007; 67(18): 8699-8707.

77. Zhao X, Zhou Y, Chen YU, Yu F. miR-494 inhibits ovarian cancer cell proliferation and promotes apoptosis by targeting FGFR2. Oncol Lett. 2016; 11(6): 4245-4251. Epub 2016 May 5.

78. Marzec-Kotarska B, Cybulski M, Kotarski JC, Ronowicz A, Tarkowski R, Polak G, et al. Molecular Bases of Aberrant miR-182 Expression in Ovarian Cancer. Genes Chromosomes Cancer. 2016. doi: $10.1002 / \mathrm{gcc} .22387$.

79. Taylor DD, Gercel-Taylor C. MicroRNA signatures of tumor-derived exosomes as diagnostic biomarkers of ovarian cancer. Gynecol Oncol. 2008; 110(1): 13-21. doi: 10.1016/j.ygyno.2008.04.033.

80. Zheng H, Zhang L, Zhao Y, Yang D, Song F, Wen Y, et al. Plasma miRNAs as diagnostic and prognostic biomarkers for ovarian cancer. PLoS One. $\quad 2013 ; \quad 8(11)$ : e77853. doi: 10.1371/journal.pone.0077853.

81. Lu L, Katsaros D, de la Longrais IA, Sochirca O, $\mathrm{Yu} \mathrm{H}$. Hypermethylation of let-7a-3 in epithelial ovarian cancer is associated with low insulin-like growth factor-II expression and favorable prognosis. Cancer Res. 2007; 67(21): 10117-10122.

82. Vogt M, Munding J, Grüner M, Liffers ST, Verdoodt B, Hauk J, et al. Frequent concomitant inactivation of $\mathrm{miR}-34 \mathrm{a}$ and $\mathrm{miR}-34 \mathrm{~b} / \mathrm{c}$ by $\mathrm{CpG}$ methylation in colorectal, pancreatic, mammary, ovarian, urothelial, and renal cell carcinomas and soft tissue sarcomas. Virchows Arch. 2011; 458(3): 313-322. doi: 10.1007/s00428-010-1030-5.

83. Yang C, Cai J, Wang Q, Tang H, Cao J, Wu L, et al. Epigenetic silencing of miR-130b in ovarian cancer promotes the development of multidrug resistance by targeting colony-stimulating factor 1 . Gynecol Oncol. 2012; 124(2): 325-334. doi: 10.1016/j.ygyno.2011.10.013.
84. Li X, Pan Q, Wan X, Mao Y, Lu W, Xie X, et al. Methylation-associated Has-miR-9 deregulation in paclitaxel- resistant epithelial ovarian carcinoma. BMC Cancer. 2015; 15: 509. doi: 10.1186/s12885015-1509-1.

85. Cai J, Yang C, Yang Q, Ding H, Jia J, Guo J, et al. Deregulation of let-7e in epithelial ovarian cancer promotes the development of resistance to cisplatin. Oncogenesis. 2013; 2: e75. doi: 10.1038/oncsis.2013.39.

86. Liu MX, Siu MK, Liu SS, Yam JW, Ngan HY, Chan DW. Epigenetic silencing of microRNA-199b$5 p$ is associated with acquired chemoresistance via activation of JAG1-Notch1 signaling in ovarian cancer. Oncotarget. 2014; 5(4): 944-958.

87. Laios A, O'Toole S, Flavin R, Martin C, Kelly L, Ring M, et al. Potential role of miR-9 and miR-223 in recurrent ovarian cancer. Mol Cancer. 2008; 7: 35. doi: 10.1186/1476-4598-7-35.

88. Resnick KE, Alder H, Hagan JP, Richardson DL, Croce CM, Cohn DE. The detection of differentially expressed microRNAs from the serum of ovarian cancer patients using a novel real-time PCR platform. Gynecol Oncol. 2009; 112(1): 55-59. doi: 10.1016/j.ygyno.2008.08.036.

89. Häusler SF, Keller A, Chandran PA, Ziegler K, Zipp K, Heuer S, et al. Whole blood-derived miRNA profiles as potential new tools for ovarian cancer screening. Br J Cancer. 2010; 103(5): 693700. doi: 10.1038/sj.bjc.6605833.

90. Chung YW, Bae HS, Song JY, Lee JK, Lee NW, $\operatorname{Kim} \mathrm{T}$, et al. Detection of microRNA as novel biomarkers of epithelial ovarian cancer from the serum of ovarian cancer patients. Int J Gynecol Cancer. 2013; 23(4): 673-679. doi: 10.1097/IGC.0b013e31828c166d.

91. Suryawanshi S, Vlad AM, Lin HM, MantiaSmaldone G, Laskey R, Lee $\mathrm{M}$, et al. Plasma microRNAs as novel biomarkers for endometriosis and endometriosis-associated ovarian cancer. Clin Cancer Res. 2013; 19(5): 1213-1224. doi: 10.1158/1078-0432.CCR-12-2726.

92. Hong F, Li Y, Xu Y, Zhu L. Prognostic significance of serum microRNA-221 expression in human epithelial ovarian cancer. J Int Med Res. 2013; 41(1): 64-71. doi: $10.1177 / 0300060513475759$.

93. Cao J, Cai J, Huang D, Han Q, Chen Y, Yang Q, et al. MiR-335 represents an independent prognostic marker in epithelial ovarian cancer. Am J Clin Pathol. 2014; 141(3): 437-442. doi: 10.1309/AJCPLYTZGB54ISZC.

94. Langhe R, Norris L, Saadeh FA, Blackshields G, Varley R, Harrison A, et al. A novel serum microRNA panel to discriminate benign from 
malignant ovarian disease. Cancer Lett. 2015; 356 :

628-636. doi: 10.1016/j.canlet.2014.10.010.

95. Wu X, Chen J, Wu M, Zhao JX. Aptamers: active targeting ligands for cancer diagnosis and therapy. Theranostics. 2015; 5(4): 322-344. doi: 10.7150/thno. 10257.

96. Marolt U, Cencic A, Gorenjak M and Potrc S. Generating Aptamers for Cancer Diagnosis and Therapy. Clin Exp Pharmacol. 2012; 2: 111.

97. Zhu Y, Chandra P, Shim YB. Ultrasensitive and selective electrochemical diagnosis of breast cancer based on a hydrazine-Au-nanoparticle-aptamer bioconjugate. Anal Chem. 2013; 85(2): 1058-1064. doi: 10.1021/ac302923k.

98. Ma F, Ho C, Cheng AKH, Yu HZ. Immobilization of redox-labeled hairpin DNA aptamers on gold: Electrochemical quantitation of epithelial tumor marker mucin 1. Electrochimica Acta. 2013; 110: 139-145.

99. Cha T, Cho S, Kim YT, Lee JH. Rapid aptasensor capable of simply diagnosing prostate cancer. Biosens Bioelectron. 2014; 62: 31-37. doi: 10.1016/j.bios.2014.06.015.

100. Van Simaeys D, López-Colón D, Sefah K, Sutphen R, Jimenez E, Tan W. Study of the molecular recognition of aptamers selected through ovarian cancer cell-SELEX. PloS One. 2010; 5(11): e13770. doi: 10.1371/journal.pone.0013770.

101. Eaton RM, Shallcross JA, Mael LE, Mears KS, Minkoff L, Scoville DJ, et al. Selection of DNA aptamers for ovarian cancer biomarker HE4 using CE-SELEX and high-throughput sequencing. Anal Bioanal Chem. 2015; 407(23): 6965-6973. doi: 10.1007/s00216-015-8665-7.

102. Hung LY, Wang CH, Hsu KF, Chou CY, Lee GB. An on-chip Cell-SELEX process for automatic selection of high-affinity aptamers specific to different histologically classified ovarian cancer cells. Lab Chip. 2014; 14(20): 4017-4028. doi: 10.1039/c4lc00587b.

103. Van Simaeys D, Turek D, Champanhac C, Vaizer J, Sefah K, Zhen J, et al. Identification of cell membrane protein stress-induced phosphoprotein 1 as a potential ovarian cancer biomarker using aptamers selected by cell systematic evolution of ligands by exponential enrichment. Anal Chem. 2014; 86(9): 4521-4527. doi: 10.1021/ac500466x. 